following reception than other medications. In my view, this issue highlights the ongoing fault lines of professional disdain and mistrust towards psychiatry among our other medical colleagues. $^{3-5}$ Solving this problem will have to go beyond the platitude of the 'additional training required' and will necessitate a significant drive to improve the image of psychiatry as a credible medical discipline.

1 Hassan L, Senior J, Edge D, Shaw J. Continuity of supply of psychiatric medicines for newly received prisoners. Psychiatrist 2011; 35: 244-8.

2 Offender Health Research Network. An Audit of Medication Prescribing Practices following Imprisonment. OHRN, 2010 (www.ohrn.nhs.uk/ resource/Research/MedicationAuditOHRN2010.pdf).

3 Craddock N, Antebi D, Attenburrow MJ, Bailey A, Carson A, Cowen P, et al. Wake-up call for British psychiatry. Br J Psychiatry 2008; 193: 6-9.

4 Brockington IF, Mumford DB. Recruitment into psychiatry. Br J Psychiatry 2002; 180: 307-12

5 Storer D. Recruiting and retaining psychiatrists. Br J Psychiatry 2002; 180: $296-7$

Trevor D. Broughton, consultant forensic psychiatrist, Norwich, UK, email: trevor.broughton@nwmhp.nhs.uk

doi: $10.1192 / p b .35 .9 .356$

\section{Emotional doctors in the house!}

Stanton et al have produced a thought-provoking study on emotional intelligence, and, in a selfless move which I hope will add to their findings that psychiatrists score highly on social responsibility scale, I would like to correct their assertion that Sir Lancelot Spratt was a product of the Carry On films. He was in fact a recurring terror in the Doctor in the House series.

1 Stanton C, Sethi FN, Dale O, Phelan M, Laban JT, Eliahoo J. Comparison of emotional intelligence between psychiatrists and surgeons. Psychiatrist 2011; 35: 124-9.

Mike Smith, Senior Psychiatric Registrar, Canterbury District Health Board, Christchurch, New Zealand, email: michael.smith@cdhb.govt.nz doi: $10.1192 /$ pb.35.9.357

\section{Change for better or worse - New Ways of Working?}

The factors psychiatrists feel induce and relieve stress in the course of their working lives, as presented in the paper by Rathod et al, are interesting and thought provoking. In our opinion, however, the findings are interpreted idiosyncratically, just possibly influenced by the first author's role as consultant in a crisis resolution and home treatment team.

The authors highlighted the finding that functional teams were rated as reducing psychiatrists' stress levels, applauding the positive effects of National Health Service (NHS) changes. Whereas consultants reported stress as a result of working across interfaces and from loss of continuity of care, Rathod et al write: 'It is the authors' opinion that it is the consequences of these changes... that are causing the stress rather than the changes per se'. So the changes are good, it is just their consequences that are bad? In fact, $21.4 \%$ of consultants in the study listed the creation of functional teams as stress reducing, whereas $49 \%$ and $44 \%$ respectively cited working across interfaces and loss of continuity of care as factors that caused stress.

New Ways of Working was introduced principally with the aim of reducing stress among psychiatrists. The possibility that the resultant loss of continuity of care, bemoaned both by patients $^{2}$ and by psychiatrists ${ }^{3}$ for its negative clinical effects, may have actually increased psychiatrists' stress levels does seem to be a most unfortunate outcome.

The counterbalance to stress in most areas of work is that of job satisfaction, a point that Rathod et al do not address. Especially at a time when recruitment into our specialty is falling, the point is an important one. For many practising psychiatrists, it is the continuity of responsibility for our case-loads of patients that provides job satisfaction and moderates stress.

If service changes have been associated with increased stress among psychiatrists and with reduced patient satisfaction, both against a backdrop of a crisis in recruiting doctors into psychiatry, is it perhaps time to think again?

1 Rathod S, Mistry M, Ibbotson B, Kingdon D. Stress in psychiatrists: coping with a decade of rapid change. Psychiatrist 2011; 35: 130-4.

2 Singhal A, Garg D, Rana AK, Naheed M. Two consultants for one patient: service users' and service providers' views on 'New Ways'. Psychiatrist 2010; 34: 181-6.

3 Dale J, Milner G. New Ways not working? Psychiatrists' attitudes. Psychiatr Bull 2009; 33: 204-7.

John M. Eagles, consultant psychiatrist, Royal Cornhill Hospital, Aberdeen, UK, email: john.eagles@nhs.net; Mugdha Kulkarni, CT 1 psychiatry, Royal Cornhill Hospital, Aberdeen.

doi: 10.1192/pb.35.9.357a

\section{Sexual Offences Act - issues where both individuals lack capacity}

Psychiatrists, especially those working with people with intellectual disabilities, may encounter situations where two individuals who engage in sexual contact both lack capacity. It may be that the contact is consensual, but it could be argued that the individuals are committing an offence, as both parties lack capacity. However, to construe the act as an offence would be tantamount to asserting that individuals lacking capacity should not engage in sexual contact, and this could be seen as an infringement of their human rights.

There is no simple answer to such a situation. The sexual contact might be grounds for initiating safeguarding procedures if there is a power imbalance between the concerned persons. Where the act is consensual, clinicians are faced with a dilemma and need to balance the patients' autonomy and rights against their professional duty of care to protect patients. A best interests meeting might help to resolve the issues and arrive at a consensus of opinion.

Prabhat Mahapatra is a consultant psychiatrist, South West Yorkshire Partnership Foundation NHS Trust, Wakefield, UK, email: prabhat.mahapatra@nhs.net, Pravati Mishra is a trust grade doctor, South West Yorkshire Partnership Foundation NHS Trust, Wakefield. doi: 10.1192/pb.35.9.357b

\section{Who should manage metabolic dysregulation?}

Bainbridge et al's paper ${ }^{1}$ on general practitioners' (GPs') attitudes on who should manage metabolic dysregulation associated with antipsychotics is interesting, topical and important, although we would like to make a couple of comments. 